\title{
Волоконно-оптические сети на основе метода квантовой коммуникации на боковых частотах
}

\author{
$\underline{\text { А.В. Глейм }}^{1,2}$, В.И. Егоров ${ }^{1, *}$, В.В. Чистяков ${ }^{1}$, А.Б. Васильев ${ }^{1}$, А.А. Гайдаш ${ }^{1}$, А.В. \\ Козубов ${ }^{1}$, С.В. Смирнов ${ }^{1}$, С.М. Кынев ${ }^{1}$, Н. В. Булдаков ${ }^{1}$, О.И. Банник ${ }^{2}$, Л.Р. \\ Гилязов ${ }^{2}$, К.С. Мельник ${ }^{2}$, Н.М. Арсланов ${ }^{2}$, С.Э. Хоружников ${ }^{1}$, С.А. Козлов ${ }^{1}$ \\ ${ }^{1}$ Университет ИТМО \\ ${ }^{3}$ Казанский квантовый центр КНИТУ-КАИ \\ *E-mail:viegorov@corp.ifmo.ru
}

DOI:10.31868/RFL2018.38-39

Технологии квантовой коммуникации (КК) позволят обеспечить безопасный информационный обмен по оптическим каналам связи в эпоху квантовых компьютеров, представляющих угрозу современным методам защиты данных [1]. Доклад посвящен результатам нескольких крупных проектов в области сетевых КК на основе метода квантовой коммуникации на боковых частотах (ККБЧ). Их результатом является запуск четырёх квантовых сетей в трех российских городах. Проекты были инициированы Университетом ITMO в период между 2014 и 2018 годами в сотрудничестве с исследовательскими центрами и коммерческими компаниями.

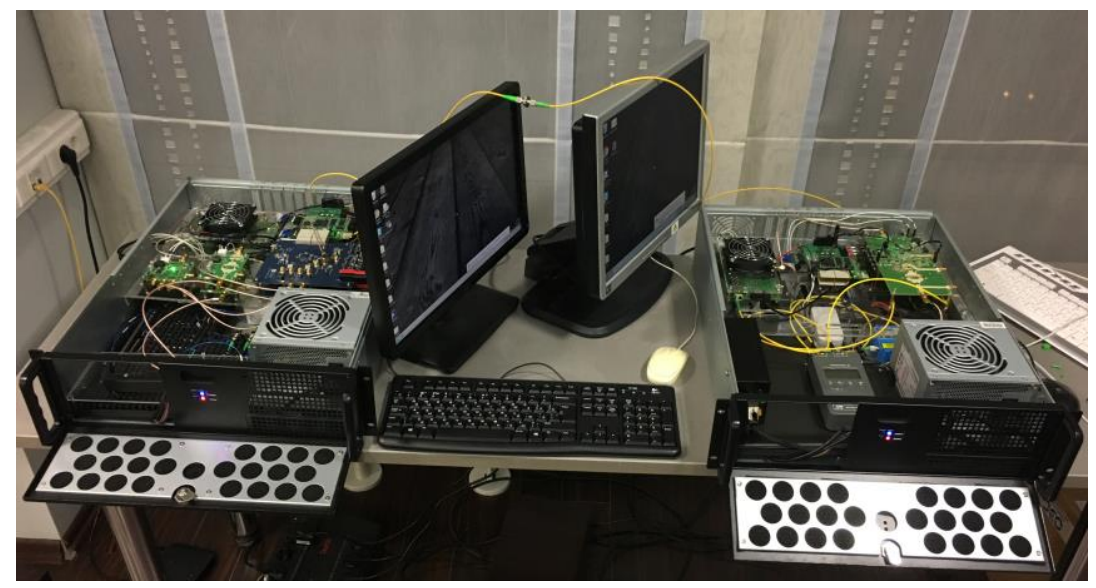

Рисунок 1 - Система ККБЧ, разработанная в Университете ИТМО

Экспериментальная установка ККБЧ (рис.1), разработанная в Университете ИТМО, использованная в сетевых экспериментах, описана в [2], обсуждение протокола доступно в [3]. Исторически первая российская квантовая сеть была запущена в 2014 году, когда квантовая линия соединила два здания в СанктПетербурге [7]. Была продемонстрирована скорость генерации просеянного ключа более 1,2 Мбит/с в канале 1,63 дБ.

Первая многопользовательская сеть ККБЧ, которая позволила продемонстрировать долгосрочную стабильность нескольких устройств, является результатом сотрудничества между Казанским квантовым центром, Университетом ИТМО и телекоммуникационным оператором ПАО «Таттелеком». Сеть соединяет четыре узла в Казани: два здания КНИТУ-КАИ и два офиса Таттелеком. Типичные скорости генерации ключей составили 20 кбит/с (в каналах 
с потерями 10 дБ) при использовании однофотонных детекторов на основе лавинных фотодиодов.

Третья квантовая сеть ККБЧ была запущена в ноябре 2017 года в Самаре в сотрудничестве с компанией «Открытый код», чтобы экспериментально продемонстрировать новый подход $к$ управлению гибридной (квантовоклассической) безопасной сетью на основе парадигмы программноконфигурируемых сетей (ПКС) [4]. Сеть включала три узла, соединенные двумя сегментами. В штатном режиме узлы 1 и 3 поддерживали квантово-зашифрованное соединение через доверенный узел 2. В случае компрометация канала ККБЧ квантовые ключи отбрасывались и сигнал о неисправности отправлялся контроллеру ПКС. Контроллер был настроен так, чтобы при отказе квантовой подсистемы автоматически переключать сеть на классические методы шифрования (SSL). Когда работа квантового канала восстанавливалась, сеть автоматически возвращалась в «квантово-защищённое» состояние. Полученные результаты важны для эффективного управления будущими многопользовательскими квантовыми сетями, которые должны быть масштабируемыми, динамически регулируемыми и не требовать вмешательства пользователя во время их нормального функционирования.

В марте 2018 года еще одна трехузловая сеть ККБЧ в Санкт-Петербурге соединила офисы производителя телекоммуникационного оборудования «Супертел», Научно-исследовательского института «Маштаб» и Технопарка Санкт-Петербурга. Эта сеть будет использоваться в качестве тестового стенда для разработки гибридных сетевых систем.

Следующим этапом в инициативе квантовой сети Университета ITMO является масштабирование линий ККБЧ от городского до национального и международного уровней. В 2017 году телекоммуникационный провайдер АО «СМАРТС» и Университет ИТМО начали проект, посвященный разработке сетей распределенных центров обработки данных с квантовой защитой.

Эти результаты лягут в основу магистральных линий КК в России, которые станут связующим звеном между европейской и китайской квантовой инфраструктурой.

\section{Литература}

1. Имре Ш. Квантовые вычисления и связь. Инженерный подход: пер. с англ. / Ш. Имре, Ф. Балаж. -М.: Физматлит, 2008.

2. J.-M. Merolla, Y. Mazurenko, J.-P. Goedgebuer, and W.T. Rhodes, Phys. Rev. Lett. -1999, V. 82, pp. 1656

3. A. V. Gleim, V. I. Egorov, Yu. V. Nazarov et al, Opt. Express, Vol. 24, No. 3, p. 2619-2633, (2016)

4. V.V. Chistyakov, O. L. Sadov, A.B. Vasiliev et al, https://arxiv.org/abs/1709.09081 